\title{
Exploring the use of 3D printing technology in the fabrication of personalised lipstick applicators
}

\begin{abstract}
This study explores the viability of applying commercially available 3D scanning and printing equipment in the development and manufacture of a personalised lipstick applicator. The shade of a lipstick and its theology are already subject to personalisation. However, the application can be achieved in a more convenient way than using a standardised swivel-up tube. The objective of this project was to examine the possibility of developing a methodology for manufacturing an innovative personalised lipstick applicator using 3D printing technology.
\end{abstract}

Keywords: acrylonitrile, UV laser, lipstick, formlab resin
Volume I Issue 4 - 2017

\section{Milica C Stevic}

Cosmetic Science Research Group, London College of Fashion, UK

\begin{abstract}
Correspondence: Milica C Stevic, Peter Hill, Slobodanka Tamburic, Cosmetic Science Research Group, London College of Fashion, University of the Arts London, 20 John Prince's Street, London WIG OBJ, UK, Tel +447847 2194 2I, Email m.stevic@fashion.arts.ac.uk
\end{abstract}

Received: November 14, 2017 | Published: December 27, 2017 


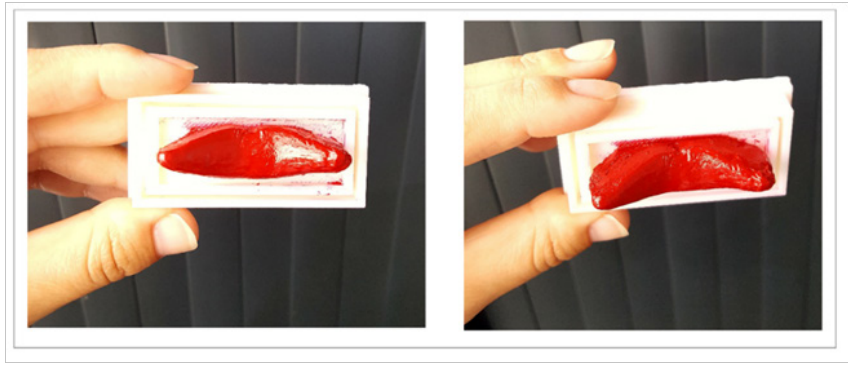

Figure 3 The final lipstick product in PLA base obtained using FDM 3D printing.

\section{Conclusion}

It was shown that a novel, bespoke, cosmetic product for the lips a personalised lipstick applicator, can be produced successfully using 3D printing technology. The FDM technique and PLA material were more effective in making personalised lipstick compared to the other studied techniques or materials.

\section{Acknowledgements}

None.

\section{Conflict of interest}

The author declares no conflict of interest.

\section{References}

1. Masri R, Driscoll CF. Clinical Applications of Digital Dental Technology. USA: John Wiley \& Sons; 2015. 250 p.

2. Pucci JU, Christophe BR, Sisti JA, et al. Three-dimensional printing: technologies, applications, and limitations in neurosurgery. Biotechnology. 2017;35(5):521-529 